\title{
The use of autologous platelet-rich plasma in the treatment of intractable skin ulcer: A case series
}

\author{
Natsuko Kakudo*, Satoshi Kushida, Tsunetaka Ogura, Tomoya Hara, Kenji Suzuki, \\ Kenji Kusumoto \\ Department of Plastic and Reconstructive Surgery, Kansai Medical University, Osaka, Japan; \\ *Corresponding Author: kakudon@takii.kmu.ac.jp
}

Received 25 September 2012; revised 23 October 2012; accepted 26 November 2012

\begin{abstract}
Platelet-rich plasma (PRP) contains a high concentration of thrombocytes and the $\alpha$-granules of platelets contain platelet-released growth factors. The usefulness of PRP for regeneration of bone and soft tissues has been reported previously. We firstly reported the efficacy of PRP prepared using the Magellan ${ }^{\circledR}$ Autologous Platelet Separator System for intractable skin ulcers such as diabetic and venous ulcers. The system consists of a microprocessor-controlled centrifuge, syringe pumps, and necessary single-use processing components. No complications occurred in any patients and the wounds achieved complete epithelialization. Our results have shown the efficiency of platelet-rich plasma for the treatment of intractable skin ulcers.
\end{abstract}

Keywords: Platelet-Rich Plasma; Chronic Wound; Wound Healing

\section{INTRODUCTION}

Platelet-rich plasma (PRP) contains a high concentration of thrombocytes and the $\alpha$-granules of platelets contain platelet-released growth factors that include molecules such as platelet-derived growth factor (PDGF), vascular endothelial growth factor (VEGF), and transforming growth factor (TGF- $\beta$ ), which stimulate cell proliferation and differentiation resulting in tissue formation $[1,2]$. Devices automatically separating PRP from whole blood have recently been developed. Among these, Arteriocyte Medical Systems Magellan ${ }^{\circledR}$ Autologous Platelet Separator System consists of a microprocessor-controlled centrifuge, syringe pumps, and necessary singleuse processing components. With the Platelet Separator Instrument, PRP is automatically and quickly separated from anticoagulated blood and dispensed into a separate sterile syringe.

Venous, diabetic, and pressure ulcers are typical chro- nic skin wounds $[3,4]$. Ulcers after a low temperature burn injury are accompanied by deep injury in many cases because the duration of exposure to the heat source is long, even though only redness and blisters are seen, and it is likely to become a chronic wound. These intractable skin wounds cause patients severe emotional and physical stress and create a significant financial burden on patients and the whole healthcare system.

We are the first to report the efficiency of PRP produced by Magellan ${ }^{\circledR}$ Autologous Platelet Separator System for intractable skin ulcers such as diabetic and venous ulcers.

\section{PATIENTS AND METHODS}

\subsection{Patient Selection}

Written informed consent was obtained from all patients undergoing PRP application. Institutional Review Board approval was also obtained. PRP was applied in five patients ( 3 men and 2 women; mean age, 54 years) who had chronic ulcers (Table 1). Full-thickness skin or soft tissue defects were present in these patients. There was no necrotic tissue in the wound, for which the risk of infection was assumed to be low, but wounds were resistant to conventional ointment treatment. Ulcer types were venous, diabetic, and pressure ulcers, and ulcers after a low temperature burn injury. The mean size of the skin and soft tissue defects was $6.3 \pm 4.4 \mathrm{~cm}^{2}$.

\subsection{Preparation of Activated Platelet-Rich Plasma (PRP)}

PRP was prepared using a Medtronic Magellan Autologous Platelet Separator (Medtronic Inc., Minneapolis, $\mathrm{MN}$ ) as previously described [5] (Figure 1(a)). Briefly, the patient's phlebotomization consisted of $60 \mathrm{~mL}$ of whole blood and was drawn from the median cubital vein with a 21-gauge needle. One $60-\mathrm{mL}$ syringe with $4 \mathrm{~mL}$ of anticoagulant citrate dextrose (ACD) solution formula A (TERUMO, Tokyo, Japan) in the syringe was used to collect blood. Blood was drawn at a slow, steady pace, 
Table 1. Patient characteristics, wound size before and after treatment, duration of wound, platelet counts of whole blood, and PRP.

\begin{tabular}{cccccccccc}
\hline $\begin{array}{c}\text { Case } \\
\text { No. }\end{array}$ & Age & Sex & $\begin{array}{c}\text { Classification } \\
\text { of ulcer }\end{array}$ & $\begin{array}{c}\text { Wound } \\
\text { area at } \\
\text { treatment } \\
\text { initiation, } \\
\left(\mathrm{cm}^{2}\right)\end{array}$ & $\begin{array}{c}\text { Wound area } \\
\text { after 4 weeks, } \\
\left(\mathrm{cm}^{2}\right)\end{array}$ & $\begin{array}{c}\text { Complete } \\
\text { healing } \\
(\text { weeks })\end{array}$ & $\begin{array}{c}\text { Platelet } \\
\text { counts of } \\
\text { whole blood } \\
\left(\times 10^{4} / \mu l\right)\end{array}$ & $\begin{array}{c}\text { Platelet } \\
\text { counts of } \\
\text { PRP } \\
\left(\times 10^{4} / \mu 1\right)\end{array}$ & $\begin{array}{c}\text { Platelet } \\
\text { concentration } \\
(\text { fold })\end{array}$ \\
\hline 1 & 76 & M & Diabetic ulcer & 9.1 & 5.2 & 14 & 13.6 & 101.1 & 7.43 \\
2 & 75 & F & Venous ulcer & 12.5 & 4.2 & 8 & 20.1 & 164.8 & 8.19 \\
3 & 28 & M & Pressure ulcer & 4.6 & Closed & 4 & 34.9 & 230.2 & 6.5 \\
4 & 63 & M & $\begin{array}{c}\text { Diabetic ulcer } \\
\text { Ulcer after a low }\end{array}$ & 2.1 & Closed & 3 & 13.6 & 94.5 & 6.94 \\
\hline
\end{tabular}

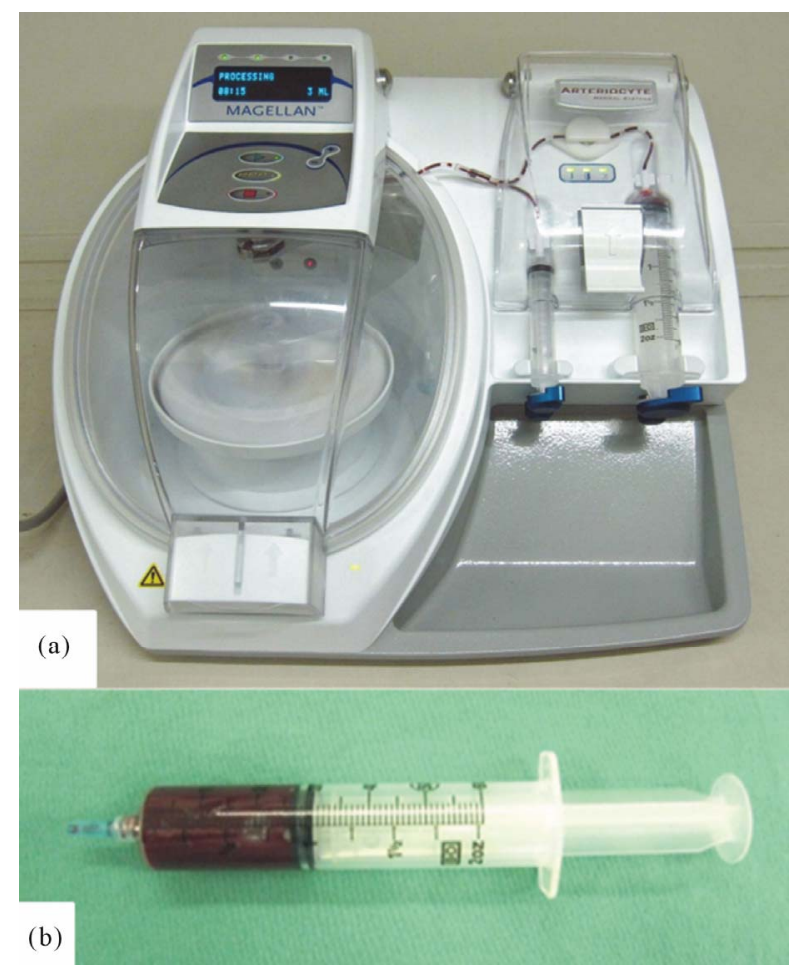

Figure 1. (a) Appearance of the Medtronic Magellan Autologous Platelet Separator; and (b) Prepared PRP.

mixing the anticoagulant with the blood at frequent intervals to prevent the formation of clots. Also at this time, $0.5 \mathrm{~mL}$ of blood was drawn in a separate tube for baseline platelet count (PLT Ct). Blood was processed with the Medtronic Magellan Autologous Platelet Separator following the manufacturer's specifications. The instrument operates by separating anticoagulated whole blood into components by centrifugation. A total of $3 \mathrm{~mL}$ of PRP was collected in a $10-\mathrm{mL}$ syringe (Figure 1(b)). PRP was mixed thoroughly by introducing a small volume of air into the syringe and gently inverting it 10 - 15 times to obtain a homogeneous mixture immediately before sampling platelet counts. A $0.5-\mathrm{mL}$ sample was sent to the laboratory for PLT Ct from the 10-mL PRP syringe. The remaining $2.5-\mathrm{mL}$ of PRP was transferred to the sterile field along with the activator. The activator, consisting of $0.5 \mathrm{M} \mathrm{CaCl}_{2}$, was prepared in advance. A 20:1 (v/v) mixture of PRP and the activator were incubated for $5 \mathrm{~min}$ at room temperature, and this mixture was regarded as activated. The activated PRP was used for the patient's wound.

\subsection{Wound Care Using PRP}

PRP was applied to the ulcer followed by occlusive dressing. The dressing was removed on day 3 of treatment; the wound surface was irrigated with physiological saline, Vaseline was applied, followed by the fabric dressing (Moiskin pad, Hakujuji Corporation, Tokyo, Japan). The fabric dressing was exchanged once after 2 - 3 days. Wounds were photographed with a scale before treatment and every week after treatment initiation using a digital camera and the ulcer area was determined using computer software (Scion Image 4.0).

\section{RESULTS}

\section{Clinical Outcomes}

Patients' data are summarized in Table 1. Application of PRP induced the formation of healthy granulation tissue and allowed successful closure of all wounds. There were no complications associated with treatment of PRP. The mean platelet concentration in PRP prepared using the Magellan system was $7.1 \pm 0.79$ times. Epithelialization of the wound took 6.6 weeks on average. The wounds of three patients were completely closed after 4 weeks and there were wound reductions after treatment in the remaining patients.

\section{CASE REPORTS}

Case 1. A 76-year-old man (Table 1, Case 1) had a diabetic ulcer $\left(9.1 \mathrm{~cm}^{2}\right)$ over the left medial lower leg 
that had not healed despite 4 months of standard conventional wound therapy (Figure 2(a)). The laboratory data of $\mathrm{HbA}_{1 \mathrm{C}}$ was $9.5 \%$. The healthy granulation tissue had developed and the wound had contraction after first PRP treatment (Figure 2(b)). PRP treatment was repeated one month later and the wound was completely epithelialized after 14 weeks (Figure 2(c)).

Case 2. A 75-year-old woman (Table 1, Case 2) had a venous ulcer $\left(12.5 \mathrm{~cm}^{2}\right)$ over the left lower leg that had

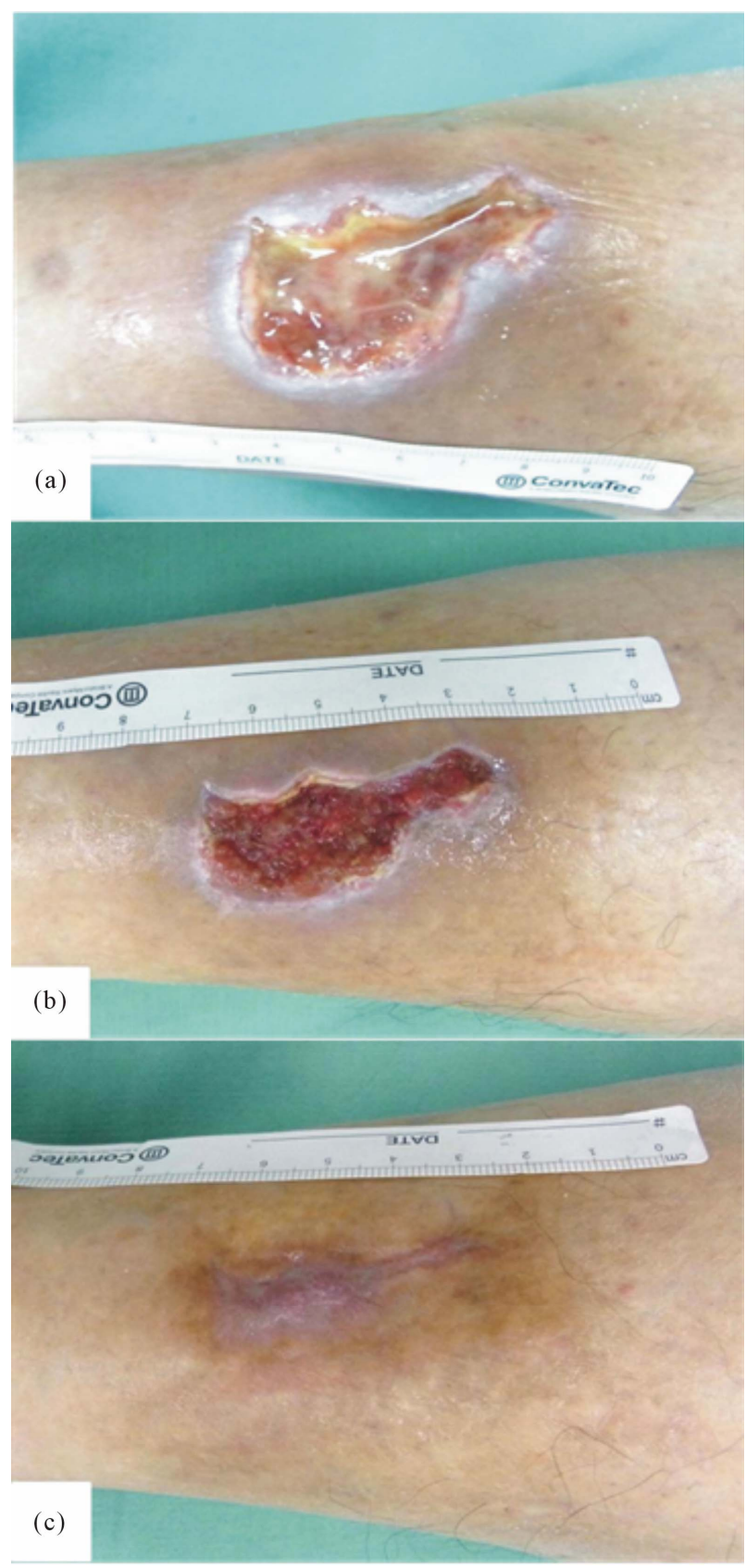

Figure 2. Case 1. (a) A $9.1 \mathrm{~cm}^{2}$ diabetic ulcer in the crus; (b) Growth of healthy granulation was noted 2 weeks after PRP treatment; and (c) Epithelialization was achieved by 2 PRP treatments. not healed despite 1 year of conventional wound therapy (Figure 3(a)). The wound was completely epithelialized after 8 weeks (Figure 3(b)).

\section{DISCUSSION}

We are the first to report the efficacy of PRP prepared using the Magellan ${ }^{\circledR}$ Autologous Platelet Separator System for chronic ulcers. No complications occurred in any patient and all wounds achieved complete epithelialization.

Platelets contribute toward hemostasis at sites of vascular injury and they contain a large number of growth factors and cytokines that play key roles in inflammation and tissue repair [1]. These characteristics of platelets have led to the idea of using platelets as therapeutic tools to promote wound healing, particularly in patients whose tissue repair is significantly impaired or delayed [1]. We previously reported that PRP promoted fibroblast growth [2] and induced epithelialization and neovascularization at split thickness skin graft donor sites [6]. Other investigators have used platelet growth factors to treat nonhealing wounds [7]. It was suggested that growth factor

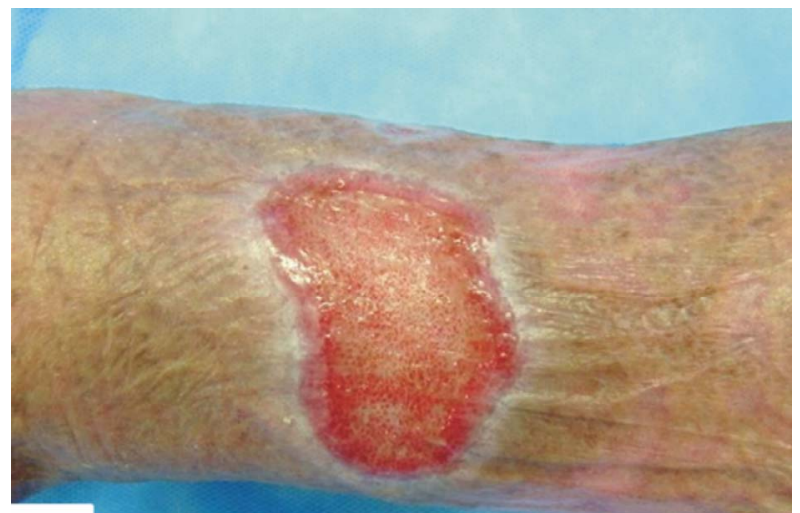

(a)

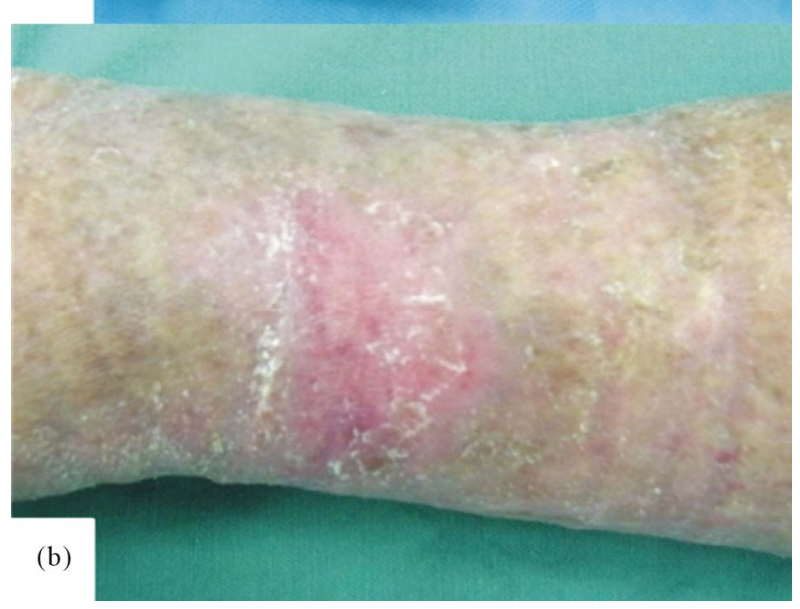

Figure 3. Case 2. (a) A $12.5 \mathrm{~cm}^{2}$ venous retention-induced ulcer in the crus; and (b) Complete epithelialization was achieved 8 weeks after PRP treatment. 
released by platelets contained in PRP promoted vascular regeneration and cell growth, leading to wound healing. It has been reported that PRP prepared using this Magel$\operatorname{lan}^{\circledR}$ Autologous Platelet Separator System was effective for the following conditions: postoperative surgical incision sites [8,9], punch biopsy wounds [10], postoperative pain after total shoulder arthroplasty [11], and bariatric surgery [5], but there has been no report on its efficacy for intractable skin ulcers such as diabetic and venous ulcers.

This study clarified that PRP at a 7.1 times concentration rate on average could be simply prepared automatically within a short time using the Magellan ${ }^{\circledR}$ Autologous Platelet Separator System, and treatment using this PRP was effective. On the basis of these results, we are running a larger study with the PRP treatment.

\section{CONCLUSION}

We are the first to report the efficacy of PRP prepared using the Magellan ${ }^{\circledR}$ Autologous Platelet Separator System for chronic ulcers. No complications occurred in any patient and all wounds achieved complete epithelialization. Our results have shown the efficiency of PRP for the treatment of intractable cutaneous ulcer such as diabetic ulcers and venous ulcers.

\section{ACKNOWLEDGEMENTS}

The authors thank Dr. Takeshi Ogawa for his skilled technical assistance. This study was partly supported by a research grant from Kansai Medical University.

\section{REFERENCES}

[1] Martin, P. (1997) Wound healing-Aiming for perfect skin regeneration. Science, 276, 75-81. doi:10.1126/science. 276.5309 .75

[2] Kakudo, N., Minakata, T., Mitsui, T., Kushida, S., Notodihardjo, F.Z. and Kusumoto, K. (2008) Proliferation-promoting effect of platelet-rich plasma on human adiposederived stem cells and human dermal fibroblasts. Plastic and Reconstructive Surgery, 122, 1352-1360.
doi:10.1097/PRS.0b013e3181882046

[3] Moreo, K. (2005) Understanding and overcoming the challenges of effective case management for patients with chronic wounds. The Case Manager, 16, 62-67.

[4] Mustoe, T. (2004) Understanding chronic wounds: A unifying hypothesis on their pathogenesis and implications for therapy. American Journal of Surgery, 187, 65S-70S. doi:10.1016/S0002-9610(03)00306-4

[5] Brady, C., Vang, S., Christensen, K., Isler, J., Vollstedt, K. and Holt, D. (2006) Use of autologous platelet gel in bariatric surgery. The Journal of Extra-Corporeal Technology, 38, 161-164.

[6] Kakudo, N., Kushida, S., Minakata, T., Suzuki, K. and Kusumoto, K. (2011) Platelet-rich plasma promotes epithelialization and angiogenesis in a splitthickness skin graft donor site. Medical Molecular Morphology, 44, 233236. doi:10.1007/s00795-010-0532-1

[7] Knighton, D.R., Ciresi, K.F., Fiegel, V.D., Austin, L.L. and Butler, E.L. (1986) Classification and treatment of chronic nonhealing wounds. Successful treatment with autologous platelet-derived wound healing factors (PDWHF). Annals of Surgery, 204, 322-330. doi:10.1097/00000658-198609000-00011

[8] Vang, S.N., Brady, C.P., Christensen, K.A., Allen, K.R., Anderson, J.E., Isler, J.R., Holt, D.W. and Smith, L.M. (2007) Autologous platelet gel in coronary artery bypass grafting: Effects on surgical wound healing. The Journal of Extra-Corporeal Technology, 39, 31-38.

[9] Englert, S.J., Estep, T.H. and Ellis-Stoll, C.C. (2008) Postoperative surgical chest and leg incision sites using platelet gel: A retrospective study. The Journal of ExtraCorporeal Technology, 40, 225-228.

[10] Hom, D.B., Linzie, B.M. and Huang, T.C. (2007) The healing effects of autologous platelet gel on acute human skin wounds. Archives of Facial Plastic Surgery: Official Publication for the American Academy of Facial Plastic and Reconstructive Surgery, Inc. and the International Federation of Facial Plastic Surgery Societies, 9, 174183. doi:10.1001/archfaci.9.3.174

[11] Zavadil, D.P., Satterlee, C.C., Costigan, J.M., Holt, D.W., Shostrom and V.K. (2007) Autologous platelet gel and platelet-poor plasma reduce pain with total shoulder arthroplasty. The Journal of Extra-Corporeal Technology, 39, 177-182. 